Revista Brasil. Bot., V.31, n.2, p.245-251, abr.-jun. 2008

\title{
Predação e parasitismo em sementes de duas populações de Parkia platycephala Benth., em áreas de cerrado no nordeste do Brasil.
}

\author{
PAULO SÉRGIO DE FIGUEIREDO ${ }^{1,2}$, EMILIA CRISTINA GIRNOS ${ }^{1} \mathrm{e}$ \\ LUCIENE SOARES SANTOS ${ }^{1}$
}

(recebido: 16 de março de 2007: aceito: 08 de maio de 2008)

\begin{abstract}
Predation and parasitism on seeds of two populations of Parkia platycephala Benth., from "cerrado" areas in Northeast Brazil). Two morphologically distinct populations of Parkia platycephala with different densities in the Cerrado, have their seeds preyed by larvae of the coleoptera Acanthoscelides imitator Kingsolver 1985, which are parasitized by the hymenoptera Stenocorse bruchivora Crawford 1900. In this study the effects of nesting, predation, and parasitism on seed germination were evaluated, and the rates of these events were compared between the two populations. Germination tests were conducted in laboratory, using four replicates of 50 seeds. Nesting, predation and parasitism rates for each population were estimated by sampling seeds from 20 fruits per individual, and from 15 individuals per population. The seeds of $P$. platycephala exhibit dormancy enforced by the seed coat. The nesting breaks the dormancy, and the pre-dispersal predation of seeds by the coleoptera larvae make them inviables. The larvae predation is biologically controlled by the hymenoptera parasitism. The seed predation rates for each population were $28 \%$ and $12 \%$, respectively, being significantly higher in the white population, which produces more and smaller seeds per fruit than the other population. The highest predation occurs because of the highest nesting rate by the coleopterans, which is positively correlated with the number of seeds per fruit. The parasitism rate was $8 \%$, approximately, and was not significantly different between the populations. The results indicate that the differences between the densities of these populations were not related to the biological interactions, as seed predation and parasitism.
\end{abstract}

Key words - "cerrado", germination, parasitism, Parkia platycephala, seed predation

RESUMO - (Predação e parasitismo em sementes de duas populações de Parkia platycephala Benth., em áreas de cerrado no nordeste do Brasil). Duas populações morfologicamente distintas de Parkia platycephala, que diferem quanto à densidade no cerrado, têm suas sementes predadas por larvas de coleópteros Acanthoscelides imitator Kingsolver 1985 as quais são parasitadas por himenópteros Stenocorse bruchivora Crawford 1900. Neste trabalho determinou-se o efeito da nidificação, predação e parasitismo na germinação das sementes, comparando-se as taxas destes eventos entre as duas populações. Os testes de germinação foram conduzidos em laboratório, utilizando-se quatro repetições de 50 sementes. As taxas de nidificação, predação e parasitismo nas populações no cerrado foram estimadas em amostras de sementes colhidas de 20 frutos por indivíduo, em 15 indivíduos por população. As sementes de P platycephala exibem dormência imposta pelo tegumento. A nidificação quebra a dormência e a predação pré-dispersão das sementes por larvas dos coleópteros as inviabiliza, sendo biologicamente controlada pelo parasitismo das larvas pelos himenópteros. A taxa de predação das sementes foi de $28 \%$ e $12 \%$ respectivamente, sendo significativamente maior na população branca com sementes menores e um maior número de sementes por fruto. A maior predação deve-se a maior taxa de nidificação das larvas dos coleópteros, a qual se correlaciona positivamente com o número de sementes por fruto. A taxa de parasitismo das larvas foi de aproximadamente $8 \%$ e não diferiu significativamente entre as populações. Os resultados indicam que a maior densidade da população branca não se deve às interações biológicas como predação ou parasitismo nas sementes.

Palavras-chave - cerrado, germinação, parasitismo, Parkia platycephala, predação de sementes

\section{Introdução}

Parkia platycephala Benth. é uma leguminosa arbórea endêmica de áreas de cerrado marginal no extremo nordeste da sua distribuição contínua, na transição para o Semi-árido. Este cerrado abrange o sul/

1. Universidade Federal do Maranhão, Campus do Bacanga, Departamento de Biologia, Av. dos Portugueses, s/n, 65068-240 São Luís, MA, Brasil

2._Autor para correspondência: paulosfigueiredo@uol.com.br sudeste do Estado do Maranhão e o noroeste do Piauí (Eiten 1972, 1994).

A espécie é característica de áreas de cerrado stricto sensu sendo observadas duas populações simpátricas morfologicamente distintas. Ambas são distinguíveis somente durante a frutificação, pois diferem com relação à coloração do fruto quando maduro. A população branca produz frutos com coloração verde e a população preta, frutos com coloração vermelho-escuro.

Os frutos são legumes indeiscentes produzidos anualmente no meio da estação seca de seis meses de 
duração, entre os meses de agosto e outubro (Bulhão \& Figueiredo 2002). No período de maturação, as sementes são predadas por coleópteros Bruchidae sendo as reservas, nos cotilédones, consumidas pelas larvas em desenvolvimento. A predação pré-dispersão das estruturas reprodutivas pode ter um efeito significativo na densidade das populações de plantas (Louda 1982, Zhang et al. 1997, Calvo-Irabie'n \& Islas-Luna 1999) sendo que, em muitos legumes, a segunda geração de Bruchidae pode virtualmente matar todas as sementes não dispersas (Janzen 1970).

Himenópteros são observados eclodindo das sementes de $P$. platycephala. O tamanho dos indivíduos adultos, o período de eclosão simultâneo ao dos coleópteros e a ausência de eclosão de coleópteros em sementes com o himenóptero, sugerem que estes sejam parasitas das larvas do coleóptero. O parasistismo, fenômeno relativamente comum nas larvas dos bruquídeos, exerce um papel importante no controle das populações sob condições naturais (Ruppert \& Barnes 1996).

Observações preliminares indicaram que as populações de $P$. platycephala diferem quanto à massa e ao número das sementes por fruto, sendo que a preta produz sementes maiores e em menor número por fruto. Ambas as populações são abundantes no cerrado da região, com a branca ocorrendo em densidade aparentemente maior.

A maior massa das sementes é uma característica de considerável valor adaptativo (Harper et al. 1970, Silvertown 1989). Em uma população, plântulas originadas de sementes maiores em massa podem emergir de profundidades maiores no solo (Yanful \& Maun 1996) e sobrevivem por mais tempo sob condições adversas como: alta taxa de desfoliação (Careaga 1989 in Paz et al. 1999), baixa luminosidade (Howe et al. 1985), baixa umidade (Manga \& Yadav 1995) e limitação de nutrientes (Allsopp \& Stock 1995). Em tese, estes fatores devem induzir um maior recrutamento de plântulas da população preta, com sementes maiores, favorecendo seu aumento populacional no cerrado. No entanto, diferenças na susceptibilidade à predação e nas taxas de parasitismo podem ter um efeito significativo na reprodução das populações de $P$. platycephala.

A preferência de bruquídeos por sementes maiores como sítio de oviposição (Moegenburg 1996, Cope \& Fox 2003), sugere que uma taxa de predação eventualmente maior em sementes da população preta atue como um fator seletivo, reduzindo sua densidade populacional no cerrado.

Neste trabalho, determinou-se o efeito da predação e do parasitismo na germinação das sementes nas duas populações de $P$. platycephala. O objetivo foi o de confirmar as interações biológicas nas sementes, verificar seu efeito na germinação e determinar se diferenças na densidade das populações podem ser relacionadas à diferenças na susceptibilidade a predação ou parasitismo nas sementes.

\section{Material e métodos}

Este trabalho foi realizado entre julho de 2003 e dezembro de 2004, numa reserva particular de cerrado pertencente à Comercial e Agrícola Paineras Ltda. A reserva possui aproximadamente 15.000 ha e compreende vários fragmentos de vegetação em diferentes níveis de conservação devido à influência antrópica. A região escolhida corresponde a um fragmento de 1.255 ha e consiste de chapadas, entrecortadas por vales, que abrigam um cerrado stricto sensu com algumas manchas de cerradão. A região é subdividida em áreas de aproximadamente 100 ha delimitadas por estradas. A área escolhida para a realização do trabalho foi um trecho de cerrado de 100 ha localizado a $3^{\circ} 20^{\prime} 41^{\prime \prime}$ S e $42^{\circ} 52^{\prime} 07^{\prime \prime} \mathrm{W}$, na altitude de 91m, no município de Santa Quitéria (MA).

A densidade das populações foi estimada pelo número de indivíduos de cada população que ocorriam em quatro parcelas de 1 ha aleatorizadas na área de 100 ha de cerrado.

Frutos e sementes foram coletados de indivíduos selecionados aleatorizando-se transecções na região central da área de 100 ha, de forma a evitar as bordas do fragmento. Foram estabelecidas seis transecções de $200 \mathrm{~m}$ de extensão, sendo a localização da primeira sorteada ao longo da coordenada norte-sul da área e as demais a cada $50 \mathrm{~m}$ de distância uma da outra, perfazendo uma área amostral de 5 ha. O critério de inclusão dos indivíduos ao longo das transecções foi arbitrário, considerando-se a necessidade de uma quantidade mínima de frutos maduros e a altura na copa inferior a 8 metros, possibilitando a coleta.

$\mathrm{O}$ número de sementes por fruto e a massa das sementes intactas foram estimados em amostras de 50 frutos por indivíduo, em 10 indivíduos por população. Para os testes de germinação e determinação das taxas de nidificação, predação e parasitismo coletou-se uma amostra de 20 frutos por indivíduo, em 15 indivíduos por população. Todas as sementes foram coletadas de frutos maduros antes da dispersão.

Para estimar a fase de desenvolvimento em que ocorre a nidificação por coleópteros, amostras de sementes imaturas em diferentes estádios de desenvolvimento foram observadas em microscópio estereoscópico (aumento 10x), sendo mantidas em quarentena, em placas de Petri, sob condições ambientais de laboratório à temperatura média de $32 / 26{ }^{\circ} \mathrm{C}(12 \mathrm{~h}$ de luz / 12 h de escuro) e umidade relativa média de $86 \%$.

A determinação do período de eclosão de coleópteros e himenópteros e as características morfológicas indicativas da nidificação, predação ou parasitismo foram observadas em sementes maduras deixadas em quarentena em placas de Petri. Após a eclosão dos coleópteros e himenópteros, as sementes foram separadas em quatro categorias: 1 . sementes 
intactas; 2. sementes com nidificação (presença de microfuro observável sob lupa e indicativo da nidificação por larvas do coleóptero); 3 . sementes predadas (presença de furo maior, de $2 \mathrm{~mm}$ de diâmetro, indicativo da eclosão do coleóptero); 4. sementes com himenóptero parasita das larvas do coleóptero (furo de tamanho intermediário, de $1 \mathrm{~mm}$ de diâmetro, indicativo da eclosão do himenóptero).

Amostras de sementes em cada categoria foram colocadas para germinar em placas de Petri, com duas folhas de papel de filtro umedecidas com água destilada. Os testes de germinação foram conduzidos em sala de germinação a temperatura ambiente $\left(32 / 26{ }^{\circ} \mathrm{C}\right)$ e luz natural difusa. Em cada tratamento foram utilizadas quatro repetições de 50 sementes por placa. O critério adotado na contagem das sementes germinadas foi a protrusão da radícula. Uma igual amostra de sementes intactas de cada população foi escarificada mecanicamente com lixa e colocada para germinar nas condições descritas acima

As freqüências de nidificação, predação e parasitismo foram estimadas por fruto e por indivíduo, contando-se o número de sementes de cada categoria da amostra de 20 frutos por indivíduo, em 15 indivíduos por população. As frequiências relativas das sementes nidificadas ou predadas foram estimadas com base no total de sementes analisadas. A frequiência relativa de parasitismo foi estimada com base no número de sementes com nidificação por larvas do bruquídeo.

Testes estatísticos paramétricos foram utilizados após o teste de normalidade de Shapiro-Wilk e do teste F para a homogeneidade das variâncias. Os dados de germinação foram normalizados utilizando-se a conversão para valores angulares (arco seno $\sqrt{\mathrm{p}}, \mathrm{p}=$ proporção de sementes germinadas). Foram utilizadas a ANOVA fatorial para comparar os efeitos da população e de tratamentos na germinação das sementes e a ANOVA seguida do teste de Tukey para comparar o efeito da predação ou parasitismo na germinação em uma mesma população.

Testes estatísticos não paramétricos foram utilizados para distribuições cuja normalidade ou homogeneidade de variâncias não foi assegurada após transformação dos dados. A densidade das populações foi comparada pelo teste de Kolmogorov-Smirnov. Os tempos médios de germinação foram estimados de acordo com Laboriau (1983). Entre populações, os tempos médios de germinação foram comparados pelo teste de Kolmogorov-Smirnov e, entre tratamentos, pelo teste de Kruskall-Wallis. A variação intrapopulacional na proporção de sementes com nidificação, predadas ou com parasitas foi comparada pelo teste de Kruskall-Wallis e as diferenças entre populações pelo teste do Qui-quadrado (Zar 1996). A correlação entre nidificação e número de sementes por fruto foi estimada por regressão linear simples e estatisticamente analisada pelo teste de significância univariado (programa "Statistic 6"). Em todos os testes o nível de significância adotado foi de 5\%.

Indivíduos adultos do coleóptero e do himenóptero parasita foram coletados, fixados e encaminhados para a identificação por especialistas.

\section{Resultados}

Os coleópteros foram identificados como Acanthoscelides imitator Kingsolver 1985 (Coleóptera, Bruchidae) e os himenópteros parasitas como Stenocorse bruchivora Crawford 1900 (Hymenoptera, Braconidae, Doryctinae). As observações das sementes, em diferentes estádios de desenvolvimento, indicaram que a nidificação por larvas de coleópteros ocorre nos estádios finais de desenvolvimento que antecedem a desidratação e sua ocorrência provoca uma perfuração no tegumento das sementes que é visível sob lupa (microfuro). Em sementes maduras de ambas as populações, a eclosão dos coleópteros e himenópteros adultos prolonga-se por 30 dias após a coleta. As larvas dos coleópteros consomem as reservas das sementes e freqüentemente o próprio embrião. A eclosão dos adultos deixa uma perfuração grande na semente, de aproximadamente $2 \mathrm{~mm}$ de diâmetro e a eclosão de himenópteros parasitas provoca uma perfuração de aproximadamente $1 \mathrm{~mm}$ de diâmetro (furo intermediário)

Na tabela 1 observa-se que a densidade das populações no cerrado difere significativamente. A população branca ocorre em densidade cerca de três vezes superior à preta, produzindo sementes menos densas e um maior número de sementes por fruto.

$\mathrm{Na}$ tabela 2 observa-se que as sementes intactas, escarificadas ou nidificadas de ambas as populações

Tabela 1. Densidade absoluta (indivíduos ha ${ }^{-1}$ ) e médias ( \pm desvio padrão) da massa e do número de sementes por frutos em duas populações morfologicamente distintas de Parkia platycephala.

(*) indicam diferenças significativas entre populações. Massa das sementes $(t=3,37, P=0,003)$, número de sementes por fruto $(t=2,13, P=0,047)$, densidade absoluta (KolmogorovSmirnov, $P \leq 0,001)$.

Table 1. Absolute density (individuals $\mathrm{ha}^{-1}$ ) and means ( \pm standart deviation) of the seed mass and the number seeds per fruit of two morphologically distinct populations of Parkia platycephala.

(*) show significant differences between the populations. Seed mass $(t=3.37, P=0.003)$, seed number per fruit $(t=2.13$, $P=0.047$ ), absolute density (Kolmogorov-Smirnov, $P \leq 0.001$ ).

\begin{tabular}{lccc}
\hline Populações & $\begin{array}{c}\text { Densidade } \\
\text { absoluta }\end{array}$ & $\begin{array}{c}\text { Massa das } \\
\text { sementes }\end{array}$ & $\begin{array}{c}\text { № de } \\
\text { sementes } \\
\text { por fruto }\end{array}$ \\
\hline Branca & $12,50^{*} \pm 3,15$ & $0,086^{*} \pm 0,01$ & $25,9^{*} \pm 2,23$ \\
Preta & $4,65 \pm 2,50$ & $0,104 \pm 0,01$ & $24,3 \pm 2,28$ \\
\hline
\end{tabular}


Tabela 2. Efeito da nidificação e da escarificação na germinação de sementes de duas populações morfologicamente distintas de Parkia platycephala. $G=$ germinação (média \pm desvio padrão), $t=$ tempo médio de germinação. Letras minúsculas comparam valores da germinação entre populações e tratamentos (ANOVA fatorial: efeito da população $(F=0,078$, $P=0,78)$, efeito do tratamento $(F=1,68, P=0,21)$, efeito da interação tratamento x população $(F=0,97, P=0,39)$. Letras maiúsculas comparam os tempos médios de germinação pelo teste de Kruskall-Wallis $(H=17,3, P=0,004)$.

Table 2. Effects of nesting and scarification on seed germination of two morphologically distinct populations of Parkia platycephala. $G=$ germination (mean \pm standart deviation), $t=$ mean time for germination. Lower cases compare germination values between populations and treatments (Factorial ANOVA: population effect $(F=0.078, P=0.78)$, treatment effect $(F=1.68, P=0.21)$, treatment x population interaction effect $(F=0.97, P=0.39)$. Capital letters compare the mean time of germination by Kruskall-Wallis test $(H=17.3, P=0.004)$.

\begin{tabular}{|c|c|c|c|c|c|c|}
\hline \multirow{2}{*}{ População } & \multicolumn{2}{|c|}{ Sementes intactas } & \multicolumn{2}{|c|}{ Sementes escarificadas } & \multicolumn{2}{|c|}{ Sementes c/ nidificação } \\
\hline & $G(\%)$ & $t$ (dias) & $G(\%)$ & $t$ (dias) & $G(\%)$ & $t$ (dias) \\
\hline Branca & $84,4^{a} \pm 6,0$ & $24,0^{\mathrm{A}} \pm 4,8$ & $85,6^{\mathrm{a}} \pm 8,2$ & $5,1^{\mathrm{B}} \pm 2,3$ & $76,9^{\mathrm{a}} \pm 3,4$ & $4,6^{\mathrm{B}} \pm 2,0$ \\
\hline Preta & $77,5^{\mathrm{a}} \pm 7,5$ & $23,6^{\mathrm{A}} \pm 5,2$ & $82,3^{a} \pm 6,8$ & $4,9^{\mathrm{B}} \pm 2,6$ & $74,2^{\mathrm{a}} \pm 9,4$ & $5,3^{\mathrm{B}} \pm 2,0$ \\
\hline
\end{tabular}

exibem uma porcentagem de germinação similar. As sementes intactas germinam em um tempo médio de aproximadamente 24 dias. Em ambas as populações, a escarificação mecânica ou a nidificação por larvas de bruquídeos reduz significativamente o tempo médio de germinação para aproximadamente 5 dias.

Na tabela 3 são apresentados os dados do efeito da predação e do parasitismo na germinação das sementes. Nas duas populações, a predação pelas larvas de

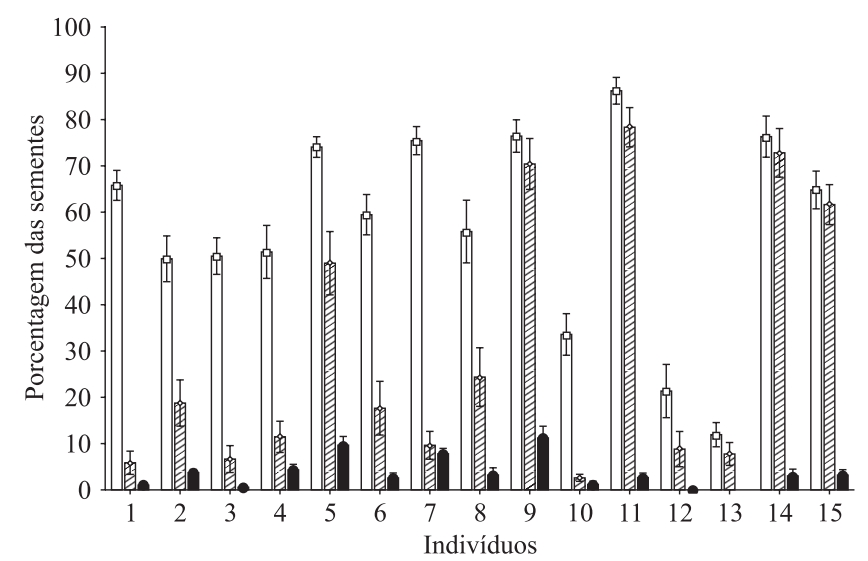

Figura 1. Variação intra-populacional na porcentagem de sementes por fruto com nidificação por coleópteros, predadas ou com himenópteros parasitas em Parkia platycephala população branca ( $\square=$ com nidificação; $\mathbb{\nabla}=$ predadas; $\square=$ com himenópteros parasitas). Barras verticais representam o erro padrão da média.

Figure 1. Intra-populational variation on the percentage of seeds per fruit with nesting by coleopterans, preyed or with hymenopterans parasites for Parkia platycephala white population ( $\square=$ with nesting; $\mathbb{\nabla}=$ preyed; $\square=$ with hymenopterans parasites). Vertical bars are standard errors. bruquídeos reduz significativamente a proporção de sementes que germina e o parasitismo das larvas por himenópteros braconídeos reverte parcialmente este efeito. O parasitismo reduz significativamente o tempo médio de germinação das sementes.

Nas figuras 1 e 2 observa-se que, em ambas as populações, a nidificação ocorre nas sementes de todos os indivíduos, variando individualmente entre $10 \%$ e $90 \%$ das sementes/fruto produzidas na população branca e

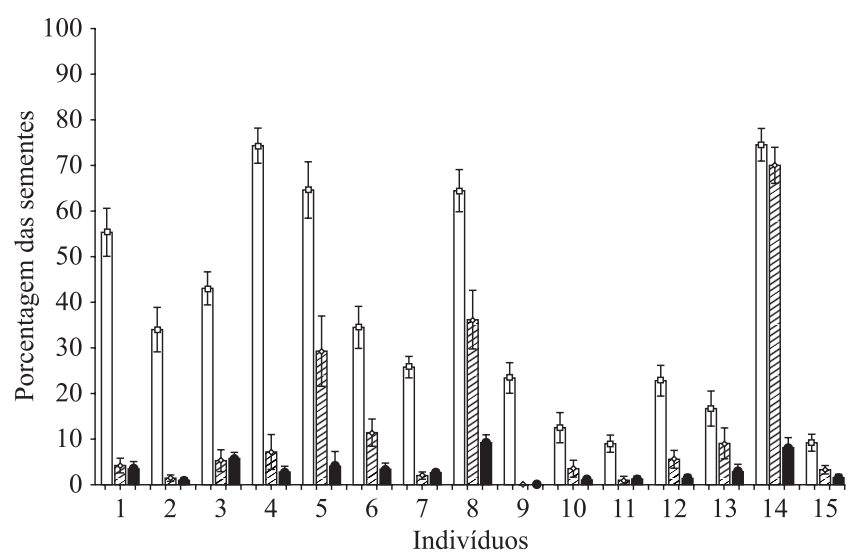

Figura 2. Variação intra-populacional na porcentagem de sementes por fruto com nidificação por coleópteros, predadas ou com himenópteros parasitas em Parkia platycephala população preta ( $\square=$ com nidificação; $\mathbb{\nabla}=$ predadas; $\square=$ com himenópteros parasitas). Barras verticais representam o erro padrão da média.

Figure 2. Intra-populational variation on the percentage of seeds per fruit with nesting by coleopterans, preyed or with hymenopterans parasites for Parkia platycephala black population ( $\square=$ with nesting; $\square=$ preyed; $\square=$ with hymenopterans parasites). Vertical bars are standard errors. 
Tabela 3. Efeito da predação e do parasitismo na germinação das sementes de duas populações morfologicamente distintas de Parkia platycephala. $G=$ germinação (média \pm desvio padrão), $t=$ tempo médio de germinação, $(-)$ não determinado. Letras comparam valores em uma mesma população. Maiúsculas comparam porcentagem de germinação (ANOVA: população branca, $F=111,4, P \leq 0,001$; população preta $F=121,8, P \leq 0,001)$ e minúsculas os tempos médios (Kolmogorov-Smirnov, $P \leq 0,05)$. Letras diferentes indicam diferenças significativas.

Table 3. Effects of predation and parasitism on seed germination of two morphologically distinct populations of Parkia platycephala. $G=$ germination (mean \pm standart deviation), $t=$ mean time for germination, $(-)$ not determined. Letters compare values in the same population. Capital letters compare the percentage of germination (ANOVA: white population, $F=111.4, P \leq 0.001$; black population, $F=121.8, P \leq 0.001$ ), and lower cases compare the mean time (Kolmogorov-Smirnov, $P \leq 0.05)$. Distinct letters show significant differences.

\begin{tabular}{|c|c|c|c|c|c|c|}
\hline \multirow{2}{*}{ População } & \multicolumn{2}{|c|}{ Sementes intactas } & \multicolumn{2}{|c|}{ Sementes predadas } & \multicolumn{2}{|c|}{ Sementes c/ parasita } \\
\hline & $G(\%)$ & $t$ (dias) & $G(\%)$ & $t$ (dias) & $G(\%)$ & $t$ (dias) \\
\hline Branca & $84,4^{\mathrm{A}} \pm 6,0$ & $24,0^{\mathrm{a}} \pm 4,8$ & $14,6^{\mathrm{C}} \pm 3,1$ & - & $61,2^{\mathrm{B}} \pm 8,1$ & $5,0^{b} \pm 1,6$ \\
\hline Preta & $77,5^{\mathrm{A}} \pm 7,5$ & $23,6^{\mathrm{a}} \pm 5,2$ & $3,2^{\mathrm{C}} \pm 0,4$ & - & $39,9^{\mathrm{B}} \pm 6,1$ & $4,9^{b} \pm 2,3$ \\
\hline
\end{tabular}

entre $10 \%$ e $75 \%$ na preta. O número de sementes predadas ou com parasitas também difere significativamente entre indivíduos. Na população branca, predação varia entre $2 \%$ e $80 \%$ das sementes produzidas e na população preta entre $0 \%$ e $70 \%$. Em ambas, o parasitismo varia entre $0 \%$ e $10 \%$ das sementes com larvas de bruquídeos.

$\mathrm{Na}$ população branca, as freqüências relativas de sementes com nidificação $(0,59)$ e de sementes predadas $(0,28)$ por larvas de coleópteros são significativamente maiores que na preta com 0,37 de nidificação e 0,12 de sementes predadas (tabela 4). A frequiência de parasitismo não difere significativamente entre as variedades e ocorre em aproximadamente $8 \%$ das sementes nas quais houve nidificação por larvas de bruquídeos.

A nidificação correlaciona-se positiva e significativamente com o número de sementes por fruto (figura 3).

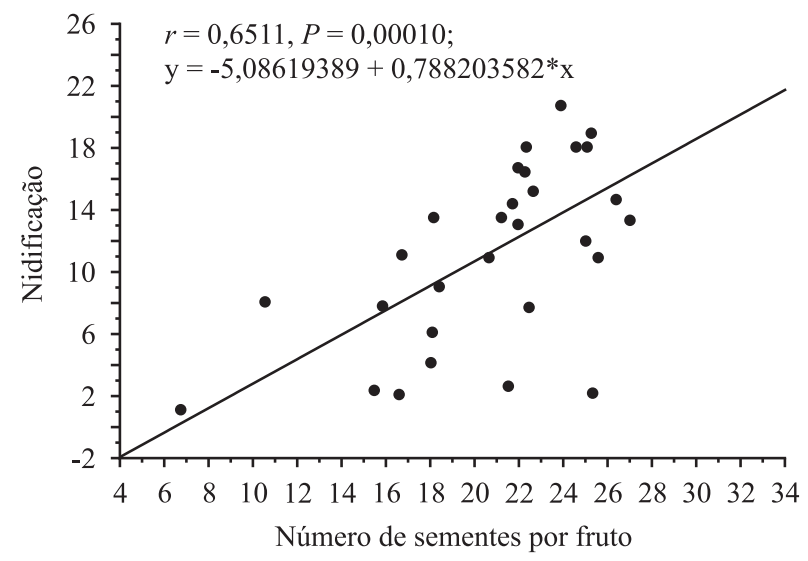

Figura 3. Correlação entre o número de sementes por fruto e nidificação em sementes de Parkia platycephala.

Figure 3. Correlation between the number of seeds per fruit and nesting in seeds of Parkia platycephala.

Tabela 4. Freqüência de nidificação, predação e parasitismo nas sementes de duas populações morfologicamente distintas de Parkia platycephala, sendo: $f \mathrm{a}=$ freqüência absoluta, $f \mathrm{r}=$ freqüência relativa. $(*)$ Indicam diferenças significativas entre populações. Nidificação $\left(\chi^{2}=2911, P \leq 0.001\right)$, predação $\left(\chi^{2}=1968,6, P \leq 0,001\right)$ e parasitismo $\left(\chi^{2}=295, P \leq 0,5\right)$.

Table 4. Frequency of nesting, predation, and parasitism on seeds of the populations of Parkia platycephala, with $f \mathrm{a}=$ absolute frequency, $f \mathrm{r}=$ relative frequency. $*$ Show significant differences between the populations. Nidification $\left(\chi^{2}=2911, P \leq 0.001\right)$, predation $\left(\chi^{2}=1968.6, P \leq 0.001\right)$, and parasitism $\left(\chi^{2}=295, P \leq 0.5\right)$.

\begin{tabular}{|c|c|c|c|c|c|c|c|}
\hline \multirow[t]{2}{*}{ População } & \multirow{2}{*}{$\begin{array}{c}\text { № de sementes } \\
\text { analisadas }\end{array}$} & \multicolumn{2}{|c|}{$\begin{array}{l}\text { № de sementes } \\
\text { com nidificação }\end{array}$} & \multicolumn{2}{|c|}{$\begin{array}{c}\text { № de sementes } \\
\text { predadas }\end{array}$} & \multicolumn{2}{|c|}{$\begin{array}{l}\text { № de sementes } \\
\text { com parasita }\end{array}$} \\
\hline & & $f \mathrm{a}$ & fr & $f \mathrm{a}$ & $f r$ & $f a$ & $\mathrm{fr}$ \\
\hline Branca & 6185 & 3613 & $0,59 *$ & 1766 & $0,28 *$ & 243 & 0,07 \\
\hline Preta & 6470 & 2404 & 0,37 & 767 & 0,12 & 201 & 0,08 \\
\hline
\end{tabular}




\section{Discussão}

As sementes de Parkia platycephala Benth, dispersas no meio da longa estação seca, são dormentes devido a baixa permeabilidade dos tegumentos à absorção de água. Quando intactas, a germinação sob hidratação contínua é lenta, prolongando-se por cerca de 60 dias (tempo médio de aproximadamente 24 dias). Esse mecanismo de dormência deve prevenir a germinação na eventualidade de chuvas esporádicas comuns no meio da seca e distribuir a germinação durante a estação chuvosa subseqüente, aumentando a probabilidade de sobrevivência das plântulas (Bewley \& Black 1994). A nidificação por larvas de Acanthoscelides imitator provoca um orifício que escarifica as sementes, quebrando sua dormência. Esse efeito é considerável dada a alta taxa de nidificação (aproximadamente $40 \%$ e $60 \%$ entre as populações) e o alto índice de insucesso no desenvolvimento de larvas de bruquídeos, evidenciada pela proporcionalmente baixa taxa de predação das sementes em ambas as populações (12\% e $28 \%$ respectivamente). Alto índice de insucesso no desenvolvimento de larvas de bruquídeos tem sido observado em sementes de outras espécies e, além do parasitismo, pode estar associado a fatores abióticos como extremos de temperatura e baixa umidade (Ramos et al. 2001), aspectos do clima que caracterizam a época da maturação e dispersão das sementes da espécie no cerrado.

A nidificação por larvas do coleóptero A. imitator ocorre em sementes imaturas no período que antecede a desidratação. As larvas desenvolvem-se durante a fase final de maturação das sementes consumindo as reservas nos cotilédones e, freqüentemente, o próprio embrião. Assim, a predação pré-dispersão as inviabiliza com as sementes predadas exibindo taxas de germinação significativamente baixas. As larvas parasitadas por himenópteros Stenocorse bruchivora não completam seu desenvolvimento e a maior parte das sementes, nas quais ocorre o parasitismo, permanece viável após a eclosão das vespas. Desta forma o parasitismo, controlando biologicamente as populações de bruquídeos, exerce um efeito direto na reprodução de Parkia platycephala reduzindo em cerca de $8 \%$ a taxa de predação das sementes.

As taxas de nidificação e de predação por larvas de bruquídeos variam significativamente entre indivíduos em ambas as populações. Grande variação intrapopulacional na taxa de predação pré-dispersão parece ser um evento comum (Ehrle'n 1996, Auld \& Denham 2001) e pode decorrer de oviposição preferencial em frutos à sombra (Traveset 1991), preferência por maior disponibilidade de frutos sob a copa (Ramos et. al. 2001), ou mesmo de uma variação espacial na densidade das populações de bruquídeos (Honek \& Martinkova 2005)

A nidificação ocorre em todos os indivíduos amostrados na população, sendo a taxa significativamente maior na população branca $(59 \%$ das sementes produzidas). A maior taxa de nidificação e maior índice de sucesso no desenvolvimento das larvas de bruquídeos nas sementes da população branca (cerca de metade das sementes com nidificação foram predadas na população branca, contra cerca de um terço na preta) determinam uma maior predação nessa população.

A maior taxa de nidificação nas sementes da população branca, que produz um maior número de sementes menores, parece contrariar a hipótese de que bruquídeos preferem sementes maiores como sítio de oviposição (Janzen, 1970, Moegenburg 1996, Cope \& Fox 2003). A correlação positiva entre a taxa de nidificação e o número de sementes por fruto sugere ser este um dos fatores relacionados à maior nidificação nas sementes da população branca, embora deva-se considerar que a preferência pode estar relacionada à outros fatores como diferenças na qualidade química das sementes entre as populações. De acordo com Birch et al. (1989), além de receptores tácteis que dão informações sobre a superfície, quimioreceptores no ovipositor das fêmeas de bruquídeos informam sobre a natureza química e teor de umidade das sementes, influenciando na escolha.

Dado que as taxas de parasitismo não diferem entre as populações e a predação é significativamente maior na população branca, sua maior densidade no cerrado não pode ser relacionada às interações biológicas nas sementes como predação e parasitismo.

Agradecimentos - Ao Professor Msc. Maurício Araújo Mendonça pelas imprescindíveis informações sobre a biologia da entomofauna associada às sementes e a Comercial e Agrícola Paineiras Ltda. pelo apoio logístico. Aos pesquisadores Dr. C.S. Ribeiro-Costa e Dr. J.A.P. Silva da Universidade Federal do Paraná, pela identificação dos bruquídeos e a Dr ${ }^{\mathrm{a}}$ Angélica M.P. Martins da Universidade Federal de São Carlos pela identificação do himenóptero parasita.

\section{Referências bibliográficas}

ALLSOPP, N. \& STOKC, W.D. 1995. Relationship between seed reserves, seedling growth and micorrhizal responses in 14 related shrubs (Rosidae) from a low-nutrient environment. Functional Ecology 9:248-54. 
AULD, T.D. \& DENHAM, A.J. 2001. Predispersal seed predation in shrubs of Grevillea (Proteaceae) from south-eastern Australia. Australian Journal of Botany 49:17-21.

BEWLEY, J. D. \& BLACK, M. 1994. Seeds: Physiology of development and germination. $2^{\text {nd }}$ ed. New York, Plenum Press.

BIRCH, A.N.E., SIMMONDS, M.S.J. \& BLANEY W.M. 1989. Chemical interactions between bruchids and legumes. In: Advances in legume biology (C.H. Stirton \& J.L. Zaruchi eds.) Missouri Botanical Garden, Missouri, p.781-809.

BULHÃO, C.F. \& FIGUEIREDO, P.S. 2002. Fenologia de leguminosas arbóreas em uma área de cerrado marginal no nordeste do Maranhão. Revista Brasileira de Botânica 25:361-370.

CALVO-IRABIE'N, L.M. \& ISLAS-LUNA, A. 1999. Predispersal predation of an understory rainforest herb Aphelandra aurantiaca (Acanthaceae) in gaps and mature forest. American Journal of Botany 86:11081113.

COPE, J.M. \& FOX, C.W. 2003. Oviposition decisions in the seed beetle, Callosobruchus maculatus (Coleoptera: Bruchidae): effects of seed size on superparasitism. Journal of Stored Products Research 39:355-365.

EITEN, G. 1972. The cerrado vegetation of Brazil. The Botanical Review 38:201-341.

EITEN, G. 1994. Duas travessias na vegetação do Maranhão. Sucesso Indústria Gráfica e Editora Ltda., São Luís.

EHRLE'N, J. 1996. Spatiotemporal variation in predispersal seed predation intensity. Oecologia 8:708-713.

HARPER, J.L., LOWELL, P.H. \& MOORE, K.G. 1970. The shapes and sizes of seeds. Annual Review of Ecology and Systematic 1:327-356.

HONEK, A. \& MARTINKOVA, Z. 2005. Pre-dispersal predation of Taraxacum officinale (dandelion) seed. Journal of Ecology 62:1-10.

HOWE, H.E., SCHUPP, E.W. \& NESLEY, L.C. 1985. Early consequences of seed dispersal for a neotropical tree (Virola surinamensis). Ecology 66:781-89.

JANZEN, D.H. 1970. Herbivores and the number of tree species in tropical forests. American Naturalist 104: 501-527.
LABOURIAU, L.F.G.A. 1983. Germinação das sementes. Secretaria Geral da Organização dos Estados Americanos, Washington.

LOUDA, S.M. 1982. Limitation of the recruitment of the shrub Haplopappus squarrosus (Asteraceae) by flower-and seed-feeding insects. Journal of Ecology 70 : 43-53.

MANGA, V.K. \& YADAV, O.P. 1995. Effect of seed size on development traits and ability to tolerate drought in pearl millet. Journal of Arid Environment 29:169172.

MOENGEMBURG, S.M. 1996. Sabal palmetto seed size: cause of variation, choices of predator and consequences for plants. Oecologia 106:539-543.

PAZ, H., MAZER S.J., MARTINEZ-RAMOS, M. 1999. Seed mass, seedling emergence, and environmental factors in seven rain forest Psychotria (Rubiaceae). Ecology 80:1594-1606.

RAMOS, F.A, MARTINS, L., FARIAS, J.M., SILVA, I.C.S., COSTA, D.C. \& MIRANDA, A.P. 2001. Oviposition and predation by Speciomerus revoili (Coleoptera, Bruchidae) on seeds of Acrocomia aculeate (Arecaceae) in Brasília, D.F., Brasil. Revista Brasileira de Biologia 61:449-454.

RUPPERT, E.E. \& BARNES, R.D. 1996. Zoologia dos Invertebrados. 6 ed. ed, Roca, São Paulo.

SILVERTOWN, J. 1989. The paradox of seed size and adaptation. Trends in Ecology and Evolution 4:24-26.

TRAVESET, A. 1991. Pré-dispersal seed predation in Central American Acacia farnesiana: factors affecting the abundance of co-occurring bruchid beetles. Oecologia 87:57-576.

YANFUL, M. \& MAUN, MA. 1996. Effects of burial of seeds and seedlings from different seed sizes on the emergence and growth of Strophostyles helvola. Canadian Journal of Botany 74:1322-1330.

ZAR, J.H.1996. Biostatistical Analyses. Prentice-Hall, New Jersey.

ZHANG, J., DRUMMOND, F.A., LIEBMAN, N. \& HATKE, A. 1997. Insect predation of seeds and plant population dynamics. Maine Agricultural and Forest Experimentation. Technical bulletin $\mathrm{n}^{\circ}-17$. University of Maine, Bangor. 